\title{
MORENO NAVARRO, ISIDORO Y DELGADO CABEZA, MANUEL (2013). Andalucía: una cultura y una economía para la vida. Sevilla: Atrapasueños Editorial y Autonomía Sur, 116 pp.
}

\author{
Jesús P. Vergara Varela \\ Universidad de Sevilla
}

A pesar de los más de treinta años transcurridos en los que Andalucía lleva contando con un Estatuto de Autonomía, parece que todavía no ha conseguido alcanzar la convergencia con el resto del Estado. O, dicho de otro modo, Andalucía no ha conseguido lograr lo que a finales de la década de los años 70 del siglo pasado parecía posible y que prometía solucionar definitivamente sus problemas estructurales, a pesar de acceder formalmente entonces a los instrumentos supuestamente necesarios.

Al menos esto es lo que se desprende de la obra de Isidoro Moreno Navarro -Catedrático de Antropología Social y Cultural por la Universidad de Sevilla y director del Grupo para el Estudio de las Identidades Socioculturales en Andalucía (GEISA)- y de Manuel Delgado Cabeza -Catedrático de Economía Aplicada y responsable del Grupo de Investigación Análisis Regional: Economía Andaluza (Area) de la Universidad de Sevilla-, una publicación de carácter divulgativo que recoge y resume buena parte de la trayectoria académica y personal que ambos autores han recorrido en su tarea de conocer y entender la realidad social y humana de Andalucía, y que también atestigua y confirma la constante actualización que han ido haciendo de sus respectivas labores tanto empírica como epistemológica, como asimismo la vigencia de sus discursos. 
Editado por la editorial Atrapasueños y Autonomía Sur -ambas entidades Sociedades Cooperativas Andaluzas- a finales de 2013, este volumen se caracteriza por su transversalidad entre dos materias que suelen a priori estimarse alejadas, como son la antropología y la economía, pero que en este caso se complementan e integran de forma crítica para analizar y dar de una forma muy didáctica una explicación al porqué de la actual situación de subalternidad de Andalucía, tanto en el estado autonómico como en el ámbito europeo. Esta situación ha continuado a pesar de las últimas décadas de transformaciones formales y de desembarco de las nuevas tecnologías, por lo que desde esta obra se plantea la necesidad de superar los vigentes marcos legales para recuperar y acercar los poderes políticos y económicos a la ciudadanía.

Dos materias, además, como ya hemos mencionado, la antropología y la economía, de vital importancia también para quienes se dedican, o al menos se acercan, al estudio de la historia, pues no solamente es importante conocer el pasado para entender el presente, sino que también a veces es necesario conocer cómo funcionan hoy ciertos mecanismos humanos para explicar cómo pudieron hacerlo ayer.

La primera parte del libro corresponde a Isidoro Moreno, que parte de la base de varios textos publicados entre los años 2002 y 2012, y en la que reflexiona sobre conceptos como el de identidad, el de memoria y el de conciencia colectiva, aplicados en este caso a la realidad contemporánea del pueblo andaluz, introducidos por un somero recorrido por los hitos que convencionalmente suelen considerarse de mayor calado histórico en la conformación de Andalucía tal y como hoy la conocemos y la entendemos.

Cuando comienza por Tartessos nos resulta inevitable recordar toda la oscilante historiografía relativa al caso, la mayor parte de ella muy politizada -como sucede con el resto de los altos picos de la historia andaluza que señala el autor y que más adelante se ven-, pero basada gran parte de la misma en cálculos y supuestos, pues el gran problema del desconocimiento que hoy seguimos arrastrando con este "foco civilizatorio" (pp. 19), que no todos los historiadores califican de "estado" (pp. 19), es el de la escasa apuesta de las administraciones públicas por la financiación de la excavación en superficie, que serviría para rellenar muchas de las lagunas que aún siguen sirviendo de caldo de cultivo para esta discusión.

La siguiente etapa destacada es la correspondiente a la Bética y su acentuada importancia en el mundo romano, a la que sigue, como no puede ser de otra manera, la época de AlAndalus. Aquí nos encontramos con un problema similar de opuestos irreconciliables, pues la falta de fuentes documentales originales de los años de la supuesta invasión árabe ha confeccionado una historiografía oficial a la que muy pocos autores se han opuesto científicamente, y los que lo han hecho ha sido casi siempre desde un cierto antiacademicismo, como en el caso del defenestrado y ya quasi mítico Ignacio Olagüe Videla (1903-1974), o desde otras materias, como la filología en el caso más actual del profesor Emilio González Ferrín (1965). 
La conquista castellana -origen tanto de los desequilibrios entre la Andalucía Baja y la Alta, como del proyecto español de estado-nación-, la edad moderna y los tempranos inicios del capitalismo son los siguientes períodos referidos, en los que no nos detenemos para no alargarnos demasiado, hasta llegar a la contemporaneidad y la autoafirmación política de Andalucía de las movilizaciones populares del 4 de diciembre de 1977 y del referéndum autonómico del 28 de febrero de 1980. Aunque se comprende por la limitación del espacio, quienes conocen la obra de Isidoro Moreno quizá echen en falta algún párrafo sobre los más treinta años de gobierno autonómico -que no autónomo, como en otras ocasiones se ha dicho-, o sobre el documento que últimamente parece que nunca existió de Estrategias y propuestas para la segunda modernización de Andalucía, editado en 2003 por un "Consejo Asesor para la Segunda Modernización" nombrado por la Junta de Andalucía, y sobre el que el autor ha publicado varios y contundentes artículos, sobre todo en la prensa.

A pesar del devenir histórico relatado y de los cambios políticos, el autor defiende en todo momento la continuidad y la pervivencia de elementos culturales e identitarios propios del territorio hoy denominado Andalucía, que permeabilizan a los que de una forma u otra se le superponen, como su constante estructuración en torno a la vida urbana, algo en lo que coincide con algunos historiadores como Antonio Domínguez Ortiz (1909-2003), cuando denominaba a Andalucía como un "país de ciudades".

Precisamente es en la identidad cultural de Andalucía en lo que se centran las páginas de la segunda parte del profesor Moreno, en la que se nos hace un breve repaso sobre algunos conceptos como etnicidad, pueblo, universalismo, marcador de identidad, o sistema de identidades, así como el porqué de la creación de unas identidades en base a la apropiación de otras, como en el caso de lo genéricamente español a partir de lo específicamente andaluz.

Aquí debemos hacer un paréntesis, pues no podemos evitar remitirnos a que es justo después del "desastre" de 1898 cuando comienzan a desarrollarse y a tomar cuerpo los regionalismos periféricos españoles contemporáneos, y cuando España, una vez perdida prácticamente toda su identidad imperial, vuelve su mirada a Andalucía para conformar su nueva personalidad con el objetivo fijado en el norte de África; y cómo durante la dictadura militar del jerezano Miguel Primo de Rivera (1923-1930), son los años en los que se consagra definitivamente la identificación de lo andaluz con lo español y viceversa, suplantándose la medieval y por entonces decadente Castilla por la potencialmente turística Andalucía -recordemos que son los años de la Exposición Iberoamericana de Sevilla de 1929-, como síntesis y personificación de las virtudes y bondades españolas. A continuación el autor nos pasa a desglosar los tres ejes o componentes estructurales que considera básicos de la identidad andaluza, de la identidad andaluza contemporánea en concreto, como son el acentuado antropocentrismo que busca unas relaciones sociales firmemente personalizadas, la negativa a la interiorización de la inferioridad 
y una consecuente ideología igualitarista, y el relativismo frente a los dogmas y los pensamientos cerrados en todas las escalas. Componentes que poseen su tesis y su antítesis, pues podemos pensar, por ejemplo, que si gracias el antropocentrismo "las relaciones anónimas tienden a ser convertidas en relaciones humanizadas” (pp. 43), quizá su versión perversa pueda encontrarse en el germen del caciquismo y el personalismo político pseudo populista del que muchas ocasiones hemos padecido en Andalucía; o que el relativismo y la permisividad, tan útiles para evitar el dogmatismo religioso, político e incluso el económico hoy día, podría ser el causante de que históricamente se hayan bloqueado en no pocas ocasiones, como apunta el propio autor, numerosos esfuerzos colectivos a medio y largo plazo.

A lo largo de la tercera y última parte, Moreno Navarro hace un alegato a la necesidad de la activación de la identidad política de Andalucía como respuesta a la postrera de las grandes "ofensivas globalizadoras" (pp. 56) en la que estaríamos inmersos, la de la mercantilización, responsable ulterior de la crisis de la democracia representativa y parlamentaria occidental. Páginas de donde podemos entresacar algunas lecturas que nos explican desde la óptica del autor muchas de las circunstancias políticas y sociales actuales, si las ponemos en relación con temas decididamente presentes como por ejemplo el vigente cuestionamiento sociológico del sistema de partidos, el elogiado por unos y denostado por otros “derecho a decidir", la recientemente aprobada Ley de Racionalización y Sostenibilidad de la Administración Local, o incluso el institucional fomento del llamado espíritu emprendedor frente a la culpabilización y casi criminalización de las personas en situación de desempleo; todo ello con pequeños guiños a las recientes movilizaciones ciudadanas acontecidas en nuestro país, y a las nuevas vías exploradas desde hace pocos años aún en algunos países de Latinoamérica, aunque con filosofías de vida centenarias, como la mencionada por el autor del "sumak kawsay" andino (pp. 67).

La segunda parte con la que nos encontramos en este libro es la correspondiente al mencionado Manuel Delgado Cabeza, que a su vez toma como base también otros textos publicados igualmente entre 2002 y 2012. De hecho, uno de estos textos de partida corresponde a su artículo "La economía andaluza durante las últimas décadas. 1981-2011", editado igual que "La identidad histórica de Andalucía" de Moreno en la obra colectiva coordinada por Celeste Jiménez de Madariaga y José Hurtado Sánchez Andalucía. Identidades culturales y dinámicas sociales (Aconcagua).

Comienza el autor con una breve introducción histórica, esta vez, obviamente, desde la ciencia económica, para explicar la configuración del capitalismo en Andalucía durante los dos últimos siglos fundamentalmente, o lo que es lo mismo, la configuración del capitalismo agrario andaluz. Una ordenación en la que desde muy pronto ya queda muy marcada la división del trabajo, tanto a nivel interno del estado español como a nivel europeo primero y mundial más tarde, y el papel que le queda asignado a Andalucía, estando los eslabones de la cadena productiva en los que se genera mayor valor añadido 
siempre fuera de sus fronteras. Es decir, un modo de funcionamiento propio de economías periféricas y coloniales que usaría nuestro territorio como mero enclave geográfico en el que encajar unas piezas que en realidad formarían parte del entramado de economías foráneas -como históricamente observamos en el estudio del primer colonialismo en otros territorios extraoccidentales como África, Sudamérica o el Sureste asiático-, y en el que el crecimiento se centra en unas pocas actividades económicas vinculadas casi siempre a la demanda exterior. Esto a su vez le hace aumentar su dependencia, con lo que podemos suponer que esto debe llevar aparejado de destrucción de las diferentes redes y tejidos productivos locales y sus respectivas potencialidades, económicas pero también sociales y culturales. Sirviéndose además de las facilidades, ayudas y subvenciones de nuestras administraciones públicas

Desde el principio del texto, y muy en la línea del autor, observamos que defiende una visión de la economía muy diferente a la que se estudia en la mayor parte de las aulas de las universidades andaluzas, aunque en todo momento los datos manejados y expuestos responden rigurosamente a fuentes oficiales como los del Ministerio de Agricultura, Alimentación y Medio Ambiente, los de la Encuesta de Población Activa (EPA) del Instituto Nacional de Estadística (INE), los derivados de la Política Agrícola Común (PAC) de la Unión Europea, así como de diferentes censos y padrones. Del mismo modo, también maneja algunos trabajos del reputado economista y estadístico José Manuel Naredo (1942), pionero en el estado español de la denominada economía ecológica. Tratándose de una obra divulgativa, quizá no hubieran sobrado algunas tablas explicativas más, sobre todo pensando en quienes nos acercamos desde otras materias y no estamos muy versados en la ciencia económica.

Una de las cuestiones que resulta más innovadora, por ser de las menos tratadas por la económica ordinaria, al menos cuando ésta se dirige al gran público, es la referente a los costos no económicos de la cada vez mayor inclusión de Andalucía en este modelo de crecimiento que, según defiende Delgado, reproduce y amplía las ya desfavorables condiciones de partida de nuestra comunidad. Unos costos sociales, culturales y ecológicos que seguramente no estén aún bien cuantificados por la "economía convencional" (pp. 77) y que ahora se están comenzando a estudiar desde ópticas críticas y alternativas, aunque aún a niveles locales, comarcales y provinciales sin la suficiente perspectiva general andaluza ${ }^{1}$.

No pasa por alto, cuando se refiere a los altos sacrificios culturales y ecológicos de la agricultura intensiva almeriense, que no se haga alguna referencia al costo humano que conlleva en cuanto a las condiciones de explotación de la mano de obra migrante,

1. Por ejemplo: VV. AA. (2011) El patrimonio de los Alcores: Una propuesta de parque cultural. Informe y propuestas sobre el patrimonio cultural, histórico-artístico, arqueológico, ambiental y paisajístico de la comarca. Sevilla: Plataforma en Defensa de los Alcores. 
especialmente subsahariana y de la Europa del Este, aunque bien es cierto que el autor ya lo trata en otros de sus trabajos en los que puede ocuparse de ello con mayor detenimiento. Con los diferentes datos, Delgado Cabeza analiza cómo desde los años 70 del siglo XX se ha ido ahondando en esta dirección de subalternidad y dependencia. Precisamente un período en el que en el Gobierno andaluz ha estado ocupado por el mismo partido político, aquel que no muchos años antes del conscientemente frustrado intento de Reforma Agraria reivindicaba la "vía yugoslava al Socialismo" y que "la autogestión significa para los trabajadores que, en lugar de vender su fuerza de trabajo a un empresario, pasarán a dirigir colectivamente cada explotación"2. Un período en que, según el autor, Andalucía ha incumplido de forma diametralmente opuesta lo recogido en sus dos estatutos de autonomía (1981 y 2007): se ha consolidado el latifundismo y el monocultivo -sobre todo del olivar-, se ha acentuado el carácter extractivo de nuestra economía de mercado sin tener en cuenta "los bienes fondo o stock de recursos" (pp. 104), ha avanzado la concentración de la población en determinadas franjas geográficas concretas, así como hemos aumentado la asimetría interna y nos hemos alejado de la prometida convergencia con respecto a los centros industrializados o desarrollados externos.

Finalmente, la actualidad del texto también se muestra palpable por sus constantes referencias a la actual crisis y sus consecuencias que ya hace unos años venimos padeciendo. Así, el autor nos habla de los 13.638 desahucios ocurridos en Andalucía durante el año 2012, a lo que podemos añadir que ya hoy sabemos que en 2013 Andalucía contaba con 637.221 viviendas vacías, mientras que, si ampliamos el marco, descubrimos que durante los tres primeros trimestres del mismo año se produjo la alarmante cifra de 49.984 desahucios en todo el estado, lo que equivale a un ritmo de 185 desahucios al día, según la estadística del Consejo General del Poder Judicial.

Para concluir, podemos decir que la obra es en sí una decidida confianza en la existencia de un futuro diferente posible para Andalucía fuera del modelo económico y social imperante que supone la actual globalización de mercado, desde el análisis científico crítico de la realidad, fomentando el debate transversal, y reivindicando como posible la enajenación del poder político del capital financiero y su devolución a la sociedad civil, siempre desde planteamientos de democracia directa y usando los instrumentos derivados de las lógicas culturales y las numerosas potencialidades que los autores ven que siguen vigentes en Andalucía.

2. VV. AA. (1977) Agricultura y Socialismo. Madrid: PSOE, pp. 63. 


\section{REFERENCIAS BIBLIOGRÁFICAS}

Agudo, Juan y Moreno, Isidoro (coords.) (2012) Expresiones culturales andaluzas. Sevilla: Aconcagua Libros.

Delgado Cabeza, Manuel (2002) Andalucía en la otra cara de la globalización: una economía extractiva en la división territorial del trabajo. Sevilla: Mergablum Edición y Comunicación SL.

González Ferrín, Emilio (2006) Historia general de Al-Andalus. Córdoba: Almuzara. Jiménez de Madariaga, Celeste y Hurtado Sánchez, José (coords.) (2012) Andalucía. Identidades culturales y dinámicas sociales. Sevilla: Aconcagua Libros.

Moreno, Isidoro (2002) La globalización y Andalucía: entre el mercado y la identidad. Sevilla: Mergablum Edición y Comunicación SL.

Olagüe, Ignacio (2004) La Revolución islámica en Occidente. Córdoba: Plurabelle. 